\title{
CT-guided iodine-125 seed permanent implantation for recurrent head and neck cancers
}

\author{
Yu L Jiang ${ }^{1}$, Na Meng ${ }^{1}$, Jun J Wang ${ }^{1 *}$, Ping Jiang ${ }^{1}$, Hui SH Yuan ${ }^{2 \dagger}$, Chen Liu², Ang Qu', Rui J Yang ${ }^{1}$
}

\begin{abstract}
Background: To investigate the feasibility, and safety of ${ }^{125} \mathrm{I}$ seed permanent implantation for recurrent head and neck carcinoma under CT-guidance.

Results: A retrospective study on 14 patients with recurrent head and neck cancers undergone ${ }^{125}$ | seed implantation with different seed activities. The post-plan showed that the actuarial D90 of ${ }^{125}$ seeds ranged from 90 to 218 Gy (median, 157.5 Gy). The follow-up was 3 to 60 months (median, 13 months). The median local control was 18 months (95\% Cl, 6.1-29.9 months), and the 1-, 2-, 3-, and 5-year local controls were 52\%, 39\%, 39\%, and $39 \%$, respectively. The 1-, 2-, 3-, and 5- survival rates were 65\%,39\%, 39\% and 39\%, respectively, with a median survival time of 20 months ( $95 \% \mathrm{Cl}, 8.7-31.3$ months). Of all patients, 28.6\% (4/14) died of local recurrence, 7.1\% (1/ 14) died of metastases, one patient died of hepatocirrhosis, and 8 patients are still alive to the date of data analysis.
\end{abstract}

Conclusion: $\mathrm{CT}_{\text {-guided }}{ }^{125}$ I seed implantation is feasible and safe as a salvage or palliative treatment for patients with recurrent head and neck cancers.

\section{Background}

Most patients who have ever undergone surgery for head and neck cancer or those local advanced or regional recurrence cancer patients received surgery combined with adjuvant external-beam radiotherapy (EBRT) $[1,2]$. Management of patients with recurrent head and neck cancers after surgery, EBRT, and adjuvant chemotherapy is a challenge for clinical oncologists. Salvage surgery is often technically feasible after the patients treated with full doses of EBRT, but the curative potential of surgery alone is low; further, the morbidity is high [3]. Redelivery of effective doses of EBRT is difficult because of the limited tolerance of adjacent normal tissues. Therefore, there has been a growing interest in combining salvage surgery with intraoperative interstitial brachytherapy [4].

Temporary intraoperative interstitial brachytherapy has its advantage in this aspect, in which a high dose of radiation is delivered directly to the cancer, while ensuring that a much lower dose is delivered to the adjacent

\footnotetext{
* Correspondence: doctorwangjunjie@yahoo.com.cn

† Contributed equally

'Department of Radiation Oncology, Peking University Third Hospital, Beijing
} 100191, PR China normal structures [5-7]. The use of high-dose rate (HDR) and low-dose rate (LDR) brachytherapy in previously irradiated regions is often safe because the use of implants ensures the delivery of the dose to very specific and limited volumes of tissue. A variety of isotopes are available for use as HDR or LDR temporary interstitial brachytherapy, but the most commonly used isotope is Iridium-192, Co-60 or Cs-137 et al, especially for treating recurrent solid cancers [8-10]. However, the use of those isotopes for intraoperative HDR brachytherapy requires very complicated shielding [11].

Computed tomography (CT)-guided permanent brachytherapy was initially used for treating liver malignancies $[12,13]$. This novel technique ensures protracted cell killing over a period of several months through targeted delivery of high-dose radiation. The advantages of this technique are as follows: (1) it is minimally invasive, (2) dose distribution can be accurately predicted, (3) continuous irradiation increases the likelihood of damaging malignant cells in a vulnerable phase of the cell cycle, and (4) the incidence rate of acute adverse effects is low.

We have gained significant experience in using permanent ${ }^{125}$ I seed implantation for treating recurrent rectal 
cancer and spinal metastases $[14,15]$. The theoretical benefit of seed permanent implantation as a salvage treatment is enhanced disease control in the region of recurrence through precise and continuous LDR irradiation, which, in turn, minimizes injury to the overlying skin and surrounding neurovascular structures.

In this study, we investigated the efficacy and feasibility of percutaneous CT-guided ${ }^{125}$ I seed permanent implantation for recurrent head and neck cancers and analyzed the local control, survival and complications of this modality.

\section{Patients and methods}

We conducted a retrospective analysis of 14 patients (median age, 40 years; range, 19-74 years) who had been treated for recurrent head and neck cancers with CTguided ${ }^{125}$ I seed permanent implantation at Peking University Third Hospital between Feb 2003 and November 2009. The study population included 9 male and 5 female patients. The criteria for eligibility were as follows: histologically proven recurrent head and neck cancer after surgery and radiotherapy, without any evidence of distant metastasis; a Karnofsky Performance Status (KPS) score $\geq 60$; and no severe impairment of kidney, liver, or bone marrow function. The diameter of recurrent tumor was less than $7 \mathrm{~cm}$. All patients had ever been reviewed by the surgeons and radiation oncologists, and were considered not suitable for salvage surgery and EBRT again or the patients refused to receive surgery and EBRT further.

Before the operation, we evaluated the history and physical condition of all the patients, hematological and chemical tests, and obtained CT images of the head and neck and radiographs of the chest. Patient characteristics are shown in Table 1.

Of the 14 patients, 2 had undergone radical surgery alone, 6 had received EBRT alone, and 6 had undergone surgery and EBRT. Two patients had undergone surgery twice and the other two patients had undergone surgery three times. Among the patients who underwent EBRT, 1,5 , and 6 patients received it 4 times, twice, and once, respectively. The total dose delivered to PTV ranged from 48.5 to $250 \mathrm{~Gy}$ (median, $70 \mathrm{~Gy}$ ). Six patients had been administered chemotherapy (3-13 cycles; median, 4 cycles). Five patients had regional recurrence in the lymph nodes and 9 patients had recurrence in the primary lesions.

A detailed CT-aided tumor-volume study was also performed for all the patients 1-2 weeks before seed implantation. We obtained transverse images of the targets at $5-\mathrm{mm}$ intervals. The images were transferred to a computerized treatment planning system (TPS, Prowess, version 3.02, SSGI, USA). The radiation oncologist outlined the planning target volume (PTV) on each
Table 1 Patient characteristics $(n=14)$

\begin{tabular}{|c|c|c|}
\hline & No. of patients & Percentage (\%) \\
\hline Median age & 40(range,19-74) & \\
\hline \multicolumn{3}{|l|}{ Gender } \\
\hline Male & 9 & 64 \\
\hline Female & 5 & 36 \\
\hline \multicolumn{3}{|l|}{ KPS } \\
\hline 60 & 1 & 7 \\
\hline 70 & 4 & 29 \\
\hline 80 & 6 & 43 \\
\hline 90 & 2 & 14 \\
\hline 100 & 1 & 7 \\
\hline \multicolumn{3}{|l|}{ Primary tumor stage } \\
\hline Stage I & 1 & 7 \\
\hline Stage II & 3 & 21 \\
\hline Stage III & 4 & 29 \\
\hline Stage IV & 5 & 36 \\
\hline Unclear & 1 & 7 \\
\hline \multicolumn{3}{|l|}{ Primary tumor } \\
\hline Sinus paranasal & 5 & 36 \\
\hline Nasopharynx carcinoma & 3 & 21 \\
\hline Larynx & 2 & 14.3 \\
\hline Hypopharyngeal carcinoma & 1 & 7 \\
\hline Nasal cavity & 1 & 7 \\
\hline Mandible & 1 & 7 \\
\hline Infratemporal fossa & 1 & 7 \\
\hline Previous surgery & 8 & 57 \\
\hline Previous chemotherapy & 6 & 43 \\
\hline Previous radiotherapy & 12 & 86 \\
\hline One & 7 & 50 \\
\hline Two & 4 & 29 \\
\hline Four & 1 & 7 \\
\hline \multicolumn{3}{|l|}{ Previous cumulative dose(Gy) } \\
\hline$\leq 50 \mathrm{~Gy}$ & 2 & 14 \\
\hline $50 \sim 100 \mathrm{~Gy}$ & 5 & 36 \\
\hline$>100 \mathrm{~Gy}$ & 5 & 36 \\
\hline Median dose(Gy) & 70(range,50-250) & \\
\hline
\end{tabular}

transverse image, to which the prescribed D90 (the doses delivered to $90 \%$ of the target volume) was prescribed. The PTV included the gross tumor volume (GTV) with a $0.5-1 \mathrm{~cm}$ margin. A radiation dose of 90160 Gy was prescribed to the PTV and calculated through computerized treatment planning system.

We had previously reported the implant technique used in this study [14]. Seed implantation was performed in all the 14 patients under local anesthesia in the CT room. After determining the target volume, 18gauge interstitial needles were inserted into the tumor through the skin surface with PTV under CT supervision. Most of the 18-gauge needles were placed $1.0 \mathrm{~cm}$ apart in a parallel array in the PTV. Precautions were taken to avoid puncturing the large vascular and neural 
structures and the bronchus. The median number of needles is 14 (range, 5-42). After placing the needles, ${ }^{125}$ I seeds (Model 6711; Beijing Atom and High Technique Industries Inc., Beijing) were implanted using a Mick applicator; the seeds were implanted $1.0 \mathrm{~cm}$ apart. All the patients received perioperative prophylactic antibiotics.

Postoperative dosimetric measurements were routinely obtained for all the patients. The implant dosimetry was determined using three-dimensional seed identification, and axial CT images (slice thickness, $5 \mathrm{~mm}$ ) of the implanted area were obtained immediately or $24 \mathrm{~h}$ after seed implantation. The CT-derived postimplant target volumes were defined to encompass the GTV with a $0.5-1 \mathrm{~cm}$ margin. The ${ }^{125} \mathrm{I}$ seeds were identified on the CT images by using a combination of manual selection and an automated redundancy check feature available on the Prowess treatment planning system. We generated isodose curves for each slice (Fig. 1) and dosevolume histograms of the target (Fig. 2). The actuarial median number of the implanted ${ }^{125}$ I seeds was 48 (range, 21-158). The specific activity of ${ }^{125} \mathrm{I}$ seeds ranged from 0.40 to $0.80 \mathrm{mCi} / \mathrm{seed}$ (median, $0.65 \mathrm{mCi}$ ). The total activity of the implanted seeds ranged from 8.8 to $113.6 \mathrm{mCi}$ (median, $24.9 \mathrm{mCi}$ ). The evaluation of post plan shown the actuarial D90 ranged from 90 to $218 \mathrm{~Gy}$ (median, $157.5 \mathrm{~Gy}$ ). The seed implanted volume ranged from 9.1 to $290.4 \mathrm{~cm}^{3}$ (median, $32 \mathrm{~cm}^{3}$ ).

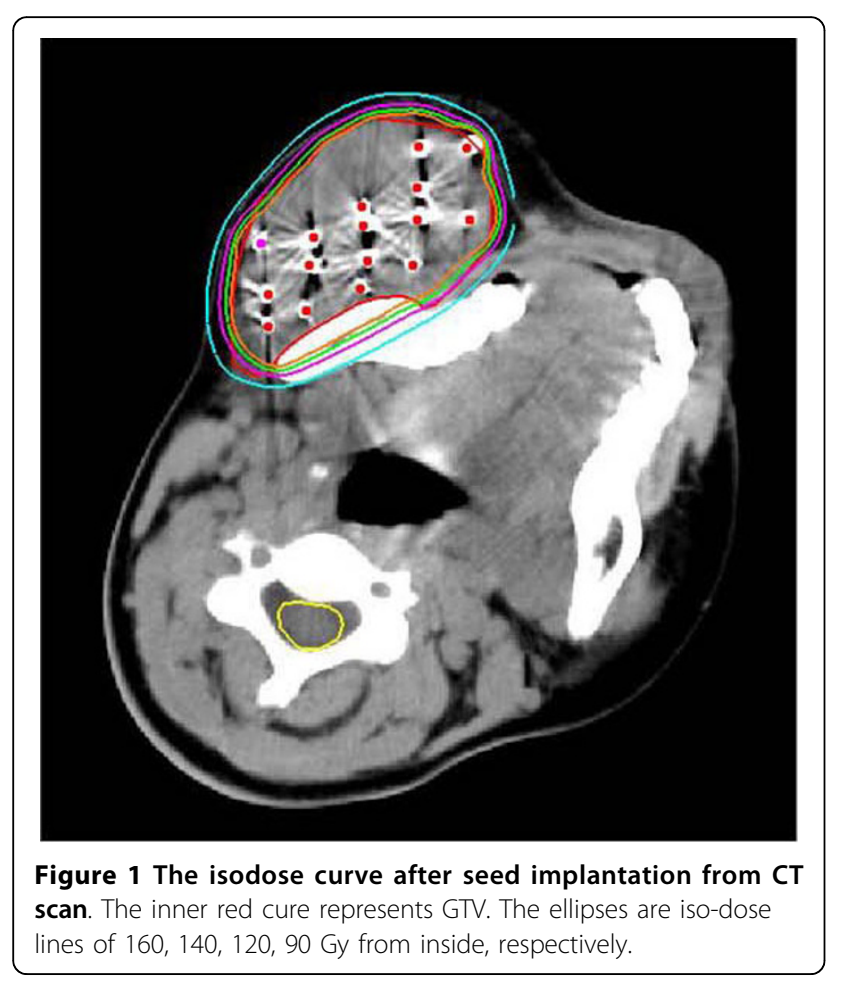

Tumor response was first evaluated at 4 weeks after implantation. Subsequent evaluations were performed at 2-3- month interval for the next 2 years and 6-month interval, thereafter. The disease status was assessed by physical examinations, liver function tests, and complete blood and platelet counts. Disease progression was determined by means of imaging studies, including CT scans and ultrasonography. The follow-up time was calculated from the date of seed implantation. The median follow-up period was 13 months (range, 3-60 months).

The complications were scored using the Radiation Therapy Oncology Group (RTOG)/European Organization for Research and Treatment of Cancer (EORCT) late radiation morbidity score [16].

The survival time was calculated from the date of implantation to the last date of follow-up or date of death. In these calculations, deaths due to any reason were scored as events. Local control was defined as the lack of tumor progression either in or adjacent to the implanted volume. Tumor responses were assessed using CT and ultrasound according to the World Health Organization (WHO) criteria [17]. The overall local control and survival times were determined using the Kaplan-Meier method by using SPSS 10.0 for Windows (SPSS, Chicago, IL).

\section{Results}

\section{Local control}

The follow-up period ranged from 3 to 60 months (median, 12 months). The median local control was 18 months (95\% CI, 6.1-29.9 months), and the 1-, 2-, 3and 5 -year local controls were $52 \%, 39 \%, 39 \%$, and $39 \%$, respectively. Of all patients, $28.6 \%(4 / 14)$ died of local recurrence, $7.1 \%(1 / 14)$ died of metastases, and 1 died of hepatocirrhosis 20 months after seed implantation and 8 still survive to the date of this analysis (Fig. 3).

\section{Survival}

The median survival time was 20 months (95\% CI, 8.731.3 months), and the 1-, 2-, 3- and 5-year survival rates were $65 \%$, 39\%, 39\%, and 39\%, respectively (Fig. 4).

\section{Complications}

One patient had grade one skin reaction, one experienced grade 1 mucosal reaction, and one developed ulceration with tumor progression after 11 months. We did not observe blood vessel damage and neuropathy in the patients.

\section{Discussion}

The treatment of patients with recurrent head and neck cancer in a previously irradiated area is particularly challenging for both surgery and EBRT. In such circumstances, redelivery of EBRT is not possible because of 


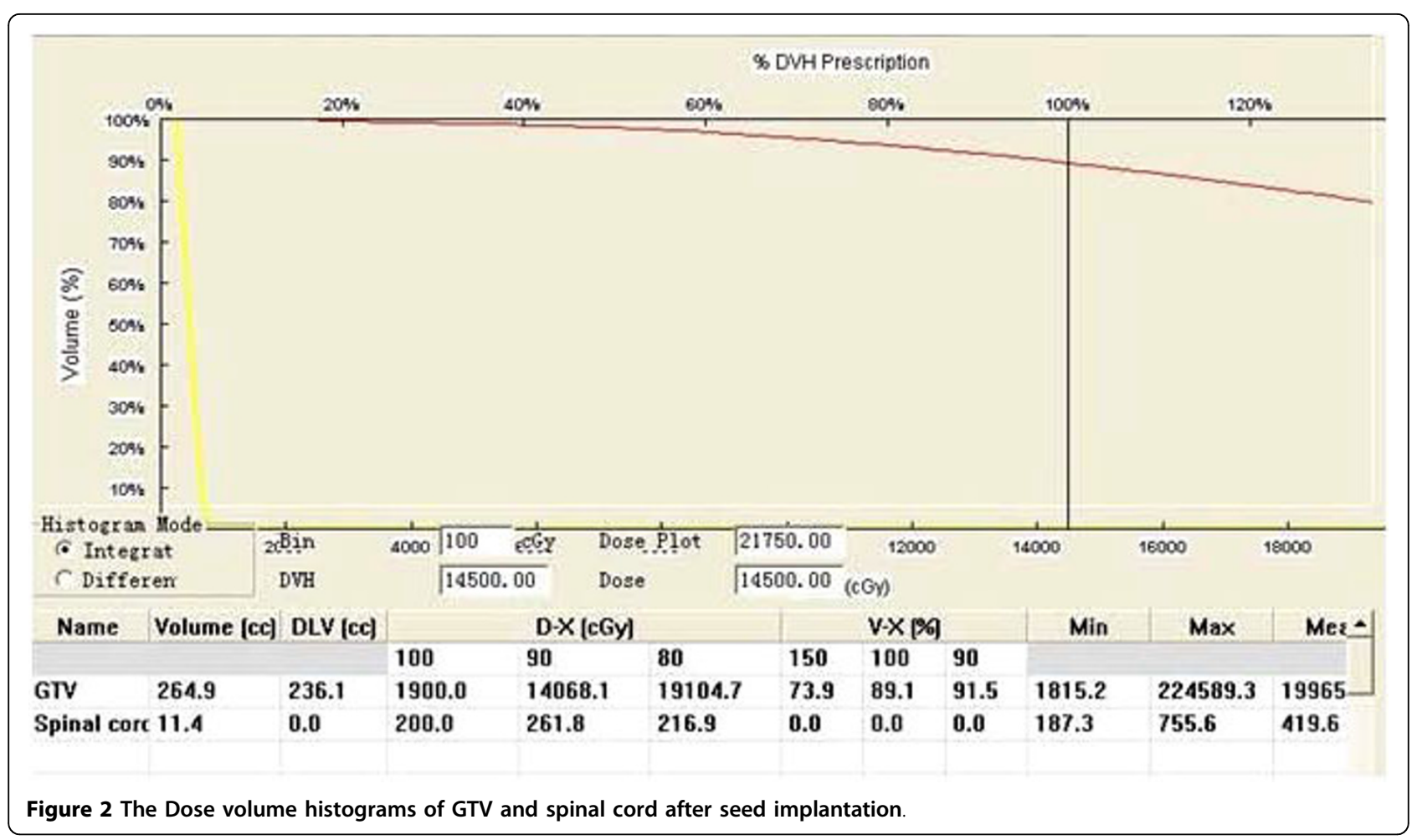

the high radiation dosage previously applied and the tolerance of adjacent normal tissue. However, local control rates of up to $50 \%$ and a 5 -year survival rate of $20 \%$ have been reported after redelivery of EBRT [18-20]. The use of re-irradiation combined with chemotherapy for recurrent head and neck carcinomas, after previous full-dose radiotherapy, has shown encouraging median survivals [21-23]. However, this approach has sometimes met some trouble for patients who have ever received

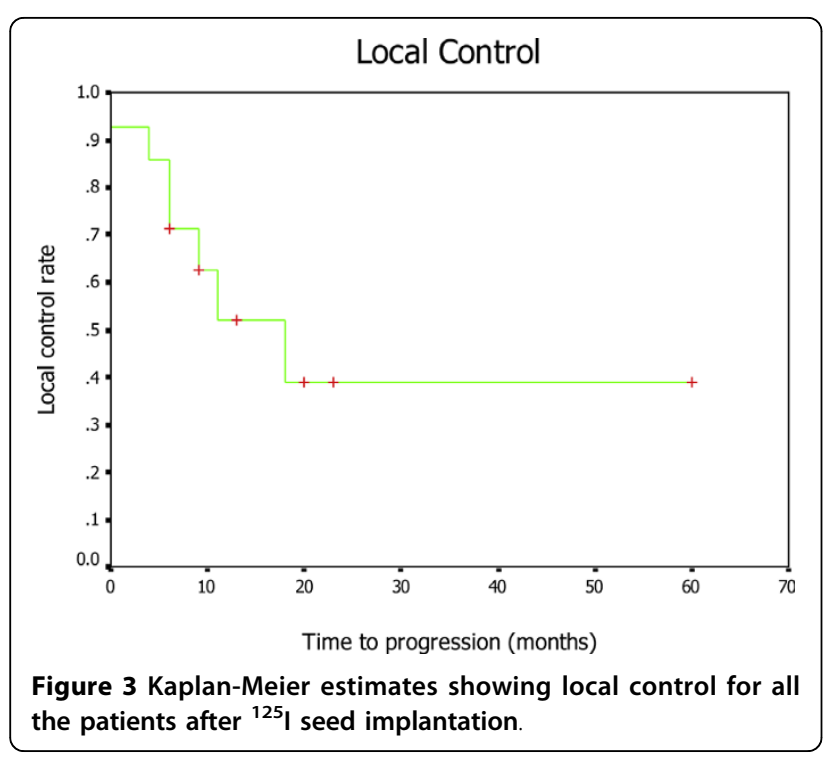

EBRT and worry about the normal tissue damages. The re-irradiation possibility is small for patients who have ever received twice EBRT, even IMRT or IGRT.

Surgery combined with intraoperative HDR interstitial brachytherapy has become a modality of salvage treatment for managing patients with locally advanced or recurrent head and neck cancer, with a local control rate of $40-60 \%$ and a 5 -year survival rate of $14 \%[24,25]$. Salvage surgery or surgery combined with intraoperative

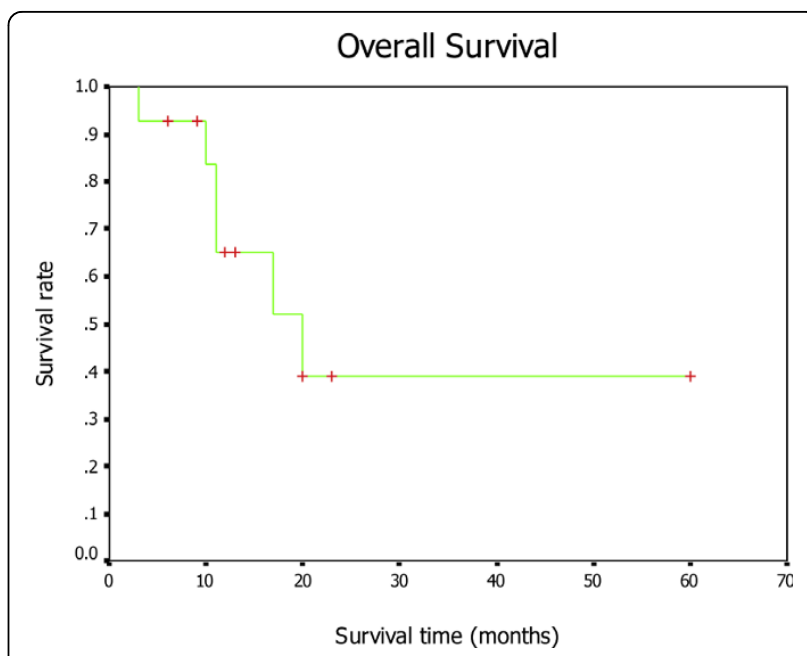

Figure 4 Kaplan-Meier estimates showing overall survival for all the patients after ${ }^{125}$ I seed implantation. 
HDR is often technically feasible, but its curative potential is low, and local failure rate is $\geq 40 \%$ [26].

Intraoperative pulsed-dose-rate (PDR) brachytherapy is an alternative reirradiation strategy that lowers the risk of severe morbidity [27]. The use of this technique resulted in excellent local control rates of up to $80 \%$ with minimal side effects when performed in carefully selected patients [28]. Intraoperation PDR imposed some practical limitations, the tumor size and location of most recurrences inhibited its application. Normal tissue fibrosis after EBRT can impair bimanual palpation of recurrent tumors during the needle implantation, the organ at risk is often in the vicinity of the tumor. The patient treatment usually lasted several days. Radium226 and iridium-192 have been used for T1 and T2 patients with oral cavity and oropharynx carcinomas and produced excellent control rates and functional results [29-33]. Vikram et al reported 124 patients with advanced recurrent head and neck cancer who were treated using ${ }^{125}$ I implants [34]; $71 \%$ of these patients showed complete regression, $18 \%$ showed $>50 \%$ regression, and $11 \%$ showed no response. Overall, local control was achieved in $64 \%$ of the patients until their deaths. Only $9 \%$ of the patients survived for 2 years and $5.5 \%$ survived for 5 years. Goffinet et al reported using permanent ${ }^{125}$ I seed implants as a surgical adjuvant in the management of patients with advanced recurrent head and neck cancer; most of the patients in this study had received prior treatment. Management involved a salvage operation combined with permanent ${ }^{125}$ I seed implants, and a local control rate of $70 \%$ had been achieved [35]. Park et al reported 35 patients with advanced recurrent squamous cell cancers of the head and neck that were treated with surgical resection followed by adjuvant ${ }^{125}$ I seed implantation. The 5 -year disease-free survival rate was $41 \%$ [36]. The use of concomitant intraoperative HDR or LDR brachytherapy has been shown to enhance actuarial survival and local control rates, but the occurrence of local complications have also been reported in 11-56\% of cases [37]. Martinez et al reported an overall complication rate of $11 \%$ [37], and Goffinet et al reported an overall complication rate of approximately 50\% [35]. The main complications were skin ulceration and wound breakdown; however, carotid rupture, which is a fatal complication, has also been occasionally reported.

Catheters are inserted during intraoperative HDR or PDR brachytherapy on the basis of preoperative images and intraoperative presentation. Planning of intraoperative HDR or PDR brachytherapy has a number of potential disadvantages: (1) the target volume and shape may change between the time of pre-plan and real time implant insertion; (2) the dose calculation is depended on pre-plan, and did not realized real time and post- plan in operation or after operation. However, imageguided seed permanent implantation overcomes these disadvantages in some selected patients. We observed a very low rate of complications, one patient had grade one skin reaction, one experienced grade one mucosal reaction, and one developed ulceration with tumor progression after 11 months, and no adverse events were attributable to seed implantation itself. One patient had ulceration because of tumor progression after seed implantation. We did not observe the occurrence of bone and soft tissue necrosis, carotid rupture, or other grade 4 or 5 toxicity.

Image-guided HDR brachytherapy for non-small-cell lung cancer and other malignancies has recently been reported by other groups [38-41]. This enables the use of circumscribed high-dose radiotherapy for the tumor target as well as the safety margin. CT-guided ${ }^{125} \mathrm{I}$ permanent seed implantation has the following advantages: (1) the implantation technique is supervised real timely on CT scan and can be performed easily under local anesthesia; (2) the possibility of target geographical miss is reduced; (3) radiation dose to the surrounding tissues is minimized due to the sharp dose fall-off outside the implanted volume, thereby lowering the morbidity; and (4) it has a shorter treatment time than re-irradiation or surgery combined with HDR. Krempien et al have reported that frameless image-guided interstitial needle implantation was feasible and accurate for 14 patients with locally recurrent head and neck cancers [42]. The 1 - and 2-year local control rates were $78 \%$ and $57 \%$, respectively, and the actuarial 1- and 2-year survival rates were $83 \%$ and $64 \%$, respectively. Image guidance allows virtual planning and navigated needle implantation, which, in turn, facilitates optimized dose distribution and reduces adjacent tissue damage.

We elaborated this technique for routine use in a large number of recurrent cancer patients by using CTguidance and routinely obtained a standard postoperative dosimetry for all patients using the 3D-CT dataset. This demonstrated that a good tumor control rate and low complication rate could be achieved using percutaneous CT-guided ${ }^{125}$ I seed permanent implantation while treating recurrent carcinomas $[14,15]$. Our results showed that the 1-, 2-, 3-, and 5-year control rates were $52 \%, 39 \%$, 39\%, and $39 \%$, respectively, with a median local control of 18 months. The 1-, 2-, 3-, and 5-year actuarial overall survival rates were $65 \%, 39 \%, 39 \%$, and $39 \%$, respectively, with a median survival of 20 months.

In conclusion, CT-guided ${ }^{125}$ I seed permanent implantation is an effective salvage modality of radiotherapy for recurrent head and neck carcinoma after previous surgery or EBRT. It eliminates the need for further surgery or EBRT, improves the outcome, and low side effects. Considering the limited number of patients involved in 
this study, arriving at a definite conclusion requires a large number of patients and long-term follow-up.

\section{Abbreviations}

The abbreviations used are: ${ }^{125}$ I: iodine-125; LDR: low-dose rate; HDR: highdose rate; SLD: sublethal damage; TPS: treatment planning system; EBRT: external beam radiotherapy; GTV: gross tumor volume; PTV: planning target volume; LR: local recurrence; CR: complete response; PR: partial response; SD: stable disease; PD: progressive disease; TTP: time to progression; OS: overall survival.

\section{Conflict of interests statement}

We disclose to Radiation Oncology the following potential conflicts of interest: this study is supported by the Fund of Capital Medical Development and Research, item NO. 2009-2024.

\section{Authors' contributions}

$Y L, N M, A Q$ and PJ participated in the data collection and performed the statistical analysis, HSY and CL carried out the needle penetration, RJY carried the dose calculation of seed implantation, JJW participated in the design of the study and seed implantation. All authors read and approved the final manuscript.

\section{Acknowledgements}

We would like to thank Dr Wei J Jiang for her skillful technical assistance, Dr Jin N Li and Su Q Tian for preparing the figures. This study was supported by the Fund of Capital Medical Development and Research, item NO. 20092024.

\section{Author details}

'Department of Radiation Oncology, Peking University Third Hospital, Beijing 100191, PR China. ${ }^{2}$ Department of Radiology, Peking University Third Hospital, Beijing, 100191, PR China.

Received: 3 June 2010 Accepted: 30 July 2010 Published: 30 July 2010

\section{References}

1. Jemal A, Siegel R, Ward E, Murray T, Xu J, Smigal C, Thun MJ: Cancer Statistics, 2006. CA Cancer J Clin 2006, 56:106-130.

2. Marcial VA, Pajak TF, Kramer S, Yupchong L, Stetz J: Radiation Oncology Group (RTOG) studies in head and neck cancer. Semin Oncol 1998, 15:39-60.

3. Ridge JA: Squamous cancer of the head and neck: Surgical treatment of local and regional recurrence. Semin Oncol 1993, 20:419-429.

4. Wang CC: Re-irradiation of recurrent nasopharyngeal carcinomatreatment techniques and results. Int J Radiat Oncol Biol Phys 1987, 13:953-956.

5. Harrison LB: Application of brachytherapy in head and neck cancer. Semi Surg Oncol 1997, 13:177-184.

6. Goffinet D, Fee WE Jr, Wells J, Austin-Seymour M, Clarke D, Mariscal JM: ${ }^{192}$ Ir pharyngoepiglottic fold interstitial implants. The key to successful treatment of bare tongue carcinoma by radiation therapy. Cancer 1985, 55:941-948.

7. Hilaris BS, Lewis JS, Henschke MK: Therapy of recurrent cancer of the nasopharynx. Arch Otolaryngol 1968, 87:506-510.

8. Wang CC, Burse K, Gitterman M: A simple afterloading applicator or intracavitary irradiation of carcinoma of the nasopharynx. Radiology 1975, 115:737-738.

9. Ash D: Interstitial therapy. Acta Radiol 1986, 16:369-393.

10. Syed AMN, Puthawala A: Afterloading interstitial implants in head and neck cancer. Arch Otolaryngol 1980, 106:541-546.

11. Lee DJ, Liberman FZ, Park RI, Zinreich ES: Intraoperative I-125 seed implantation for extensive recurrent head and neck carcinomas. Radiology 1991, 178:879-882.

12. Ricke J, Wust P, Stohlmann A, Beck A, Cho CH, Pech M, Wieners G: CTguided brachytherapy. A novel percutaneous technique for interstitial ablation of liver malignancies. Strahlenther Onkol 2004, 180:274-280.

13. Ricke J, Wust P, Stohlmann A, Beck A, Cho CH, Seidensticker M, Wieners $G$, Spors B, Werk M, Rosner C: CT-guided brachytherapy of liver malignancies alone or in combination with thermal ablation: phase I-II results of a novel technique. Int I Radiat Oncol Biol Phys 2004, 58:1496-1505.

14. Jun JW, Hui ShuY, Ji NL, Wei JJ, Yu L, Su QT: Interstitial permanent implantation of ${ }^{125}$ s seeds as salvage therapy for re-recurrent rectal carcinoma. Int J Colorectum Dis 2009, 24:391-399.

15. Jun JW, Hui ShuY, Qing JM, Xiao GL, Hao W, Yu LJ, Su QT, Rui JY: Interstitial ${ }^{125}$ I seeds implantation to treat spinal metastatic and primary paraspinal malignancies. Med Oncol 2009, 10.1007/s12032-009-9212-1.

16. Cox JD, Stetz J, Pajak TF: The toxicity criteria of the Radiation Therapy Oncology for Research and Treatment of Cancer (EORTC). Int I Radiat Oncol Biol Phys 1995, 31:1341-1346.

17. Miller $A B$, Hoogstraten $B$, Staquet $M$, Winkler A: Reporting results of cancer treatment. Cancer 1981, 47:207-214

18. Emami B, Bignardi M, Devineni VR, Spector GJ, Hederman MA: Reirradiation of head and neck cancer. Laryngoscope 1987, 97:85-88.

19. Kennedy JT, Krause CJ, Loevy S: The importance of tumor attachment to the carotid artery. Arch Otolaryngol Head Neck Surg 1977, 103:70-73.

20. Langois D, Eschwege F, Kramer A, Richard JM: Re-irradiation of head and neck cancers. Radiother Oncol 1985, 3:27-33.

21. Pomp J, Levendage PC, van Putten WL: Re-irradiation with recurrent tumors in the head and neck. Am J Clin Oncol 1988, 11:543-549.

22. Spencer SA, Harris J, Wheeler RH, Machtay M, Schultz C, Spanos W, Rotman M, Spanos W, Rotman M: RTOG 96-10: Re-irradiation with concurrent hydroxyurea and 5-flurouracil in patients with squamous cell cancer of the head and neck. Int J Radiat Oncol Biol Phys 2001, 51:1299-1304.

23. Stevens KR, Britsch A, Moss WT: High-dose re-irradiation of head and neck cancer with curative intent. Int J Radiat Oncol Biol Phys 1994, 29:687-698.

24. Emami B, Marks JE: Re-irradiation of recurrent carcinoma of the head and neck by afterloading interstitial 192Ir implant. Laryngoscope 1983, 93:1345-1347.

25. Mazeron JJ, Langlolis D, Glaubinger D, Huart J, Martin M, Raynal M, Calitchi E, Ganem G: Salvage irradiation of oropharyngeal cancers using iridium 192 wire implants: 5-year results of 70 cases. Int J Radiat Oncol Biol Phys 1987, 13:957-962.

26. Puthawala AA, Syed AMN: Interstitial re-irradiation for recurrent and/or persistent head and neck cancers. Int I Radiat Oncol Biol Phys 1987, 13:1113-1114.

27. Geiger M, Strnad V, Lotter M, Sauer R: Pulsed-dose rate brachytherapy with concomitant chemotherapy and interstitial hyperthermia in patients with recurrent head-and -neck cancer. Brachytherapy 2002, 1:149-153.

28. Strnad V, Geiger M, Lotter M, Sauer R: The role of pulsed-dose-rate brachytherapy in previously irradiated head-and-neck cancer. Brachytherapy 2003, 2:158-163.

29. Senan S, Levendage PC: Brachytherapy for recurrent head and neck cancer. Hematol Oncol Clin North Am 1999, 13:531-542.

30. Decroix $Y$, Ghossein NA: Experience of the Curie Institute in treatment of cancer of the mobile tongue. Cancer 1981, 47:496-502.

31. Gilbert EH, Goffinet DR, Ragshaw WA: Carcinoma of the oral tongue and floor of mouth: Fifteen years experience with linear accelerator therapy. Cancer 1975, 35:1517-1524.

32. Shasha D, Harrison LB, Chiu-Tsao ST: The role of brachytherapy in head and neck cancer. Semin Radiat Oncol 1998, 8:270-281.

33. Fee WE, Goffinet DR, Paryani S, Goode RL, Levine PA, Hopp ML: Intraoperative lodine-125 implants. Arch Otolaryngol 1983, 109:727-730

34. Vikram B, Hilaris BS, Anderson L, Strong EW: Permanent iodine-125 implants in head and neck cancer. Cancer 1983, 51:1310-1314.

35. Goffinet DR, Martinez A, Fee WE Jr: I-125 vicry suture implants as a surgical adjuvant in cancer of the head and neck. Int $J$ Radiat Oncol Biol Phys 1985, 11:399-402.

36. Park RI, Liberman FZ, Lee DJ, Goldsmith MM, Price J: lodine-125 seed implantation as an adjuvant to surgery in advanced recurrent squamous cell cancer of the head and neck. Laryngoscope 1991, 101:405-410.

37. Martinez A, Goffinet DR, Fee W, Goode R, Cox RS: lodine-125 implants as an adjuvant to surgery and external beam radiotherapy in the management of locally advanced head and neck cancer. Cancer 1983, 51:973-979. 
38. Ricke J, Wust P, Wieners G, Hengst S, Pech M, Hanninen EL, Felix R: CTguided interstitial single fraction HDR brachytherapy of lung tumors: Phase I results of a novel technique. Chest 2005, 127:2237-2242.

39. Krempien RC, Grehn C, Haag C, Straulino A, Hensley EW, Kotrikova B, Hofele Ch, Debus J, Harms W: Feasibility report for retreatment of locally recurrent head-and neck cancers by combined brachytherapy using frameless image-guided $3 \mathrm{D}$ interstitial brachytherapy. Brachytherapy 2005, 4:154-162.

40. Harms W, Krempien R, Grehn C, Hensley F, Debus J, Becker HD:

Electromagnetically navigated brachytherapy as a new treatment option for peripheral pulmonary tumors. Strahlenther Onkol 2006, 182:108-111.

41. Griffin PC, Amin PA, Hughes P, Levine AM, Sewchand WW, Salazar OM: Pelvic mass: $\mathrm{CT}$-guided interstitial catheter implantation with high-doserate remote afterloader. Radiology 1994, 191:581-583.

42. Kolotas C, Baltas D, Zamboglu N: CT-based interstitial HDR brachytherapy. Strahlenther Onkol 1999, 175:419-427.

doi:10.1186/1748-717X-5-68

Cite this article as: Jiang et al: CT-guided iodine-125 seed permanent implantation for recurrent head and neck cancers. Radiation Oncology 2010 5:68.

\section{Submit your next manuscript to BioMed Central} and take full advantage of:

- Convenient online submission

- Thorough peer review

- No space constraints or color figure charges

- Immediate publication on acceptance

- Inclusion in PubMed, CAS, Scopus and Google Scholar

- Research which is freely available for redistribution

Submit your manuscript at www.biomedcentral.com/submit 